\title{
De novo expression of Trpm4 initiates secondary hemorrhage in spinal cord injury
}

\author{
Volodymyr Gerzanich $^{1}$, S Kyoon Woo ${ }^{1}$, Rudi Vennekens ${ }^{2}$, Orest Tsymbalyuk ${ }^{1}$, Svetlana Ivanova ${ }^{1}$, \\ Alexander Ivanov ${ }^{1}$, Zhihua Geng ${ }^{1}$, Zheng Chen ${ }^{1}$, Bernd Nilius ${ }^{2}$, Veit Flockerzi ${ }^{3}$, Marc Freichel ${ }^{3}$ \& \\ J Marc Simard ${ }^{1,4,5}$
}

\begin{abstract}
The role of transient receptor potential M4 (Trpm4), an unusual member of the Trp family of ion channels, is poorly understood. Using rodent models of spinal cord injury, we studied involvement of Trpm4 in the progressive expansion of secondary hemorrhage associated with capillary fragmentation, the most destructive mechanism of secondary injury in the central nervous system. Trpm4 mRNA and protein were abundantly upregulated in capillaries preceding their fragmentation and formation of petechial hemorrhages. Trpm4 expression in vitro rendered COS-7 cells highly susceptible to oncotic swelling and oncotic death following ATP depletion. After spinal cord injury, in vivo gene suppression in rats treated with Trpm4 antisense or in Trpm4 ${ }^{-I_{-}^{-}}$mice preserved capillary structural integrity, eliminated secondary hemorrhage, yielded a threefold to fivefold reduction in lesion volume and produced a substantial improvement in neurological function. To our knowledge, this is the first example of a Trp channel that must undergo de novo expression for manifestation of central nervous system pathology.
\end{abstract}

The mammalian transient receptor potential (Trp) superfamily includes 28 nonselective cation channels, most of which conduct both monovalent and divalent cations. Trp channels have numerous critical roles in diverse homeostatic functions involving transport of ions across cell membranes ${ }^{1,2}$. Two members of the melastatin family, Trpm4 and Trpm5, are unusual in that they conduct monovalent cations exclusively and are impermeable to divalent cations. So far, the only role suggested for Trpm4 is that, when activated, it protects against $\mathrm{Ca}^{2+}$ overload by depolarizing the cell, thereby decreasing the driving force for $\mathrm{Ca}^{2+}$ influx ${ }^{3-5}$.

Some Trp channels have been linked to various disease processes ${ }^{1,6}$, with most Trp "channelopathies" being associated with loss of constitutive function. Trpm 2 and Trpm7 have been implicated in $\mathrm{Ca}^{2+}$-mediated anoxic death of neurons in vitro ${ }^{7,8}$. However, to our knowledge, no Trp channel has previously been identified that must undergo de novo expression for manifestation of central nervous system (CNS) pathology.

Contusion of the CNS involving brain or spinal cord injury (SCI) is frequently complicated by "blossoming" or expansion of the hemorrhage ${ }^{9,10}$. Although sometimes erroneously attributed to continued bleeding of vessels fractured by the original trauma, this phenomenon represents a secondary pathological process, as suggested by delayed appearance of distinct islands of hemorrhage segregated from the original site of impact. Expansion of secondary hemorrhage occurs during the first several hours after a traumatic insult. It results from progressive catastrophic failure of the structural integrity of capillaries $^{11}$ and is characterized by formation of small, discrete satellite (petechial) hemorrhages in spinal cord tissues surrounding the site of primary injury ${ }^{12}$. With time, petechial hemorrhages increase in number and eventually coalesce into a hemorrhagic lesion that encompasses a volume far greater than the site of primary injury ${ }^{13}$. Secondary hemorrhage is particularly damaging because it greatly expands the volume of neural tissue destroyed by the primary injury. The capillary dysfunction implicit with secondary hemorrhage causes tissue ischemia and hypoxia ${ }^{14}$, and the blood is exquisitely toxic to CNS cells ${ }^{15,16}$, further injuring neural tissues owing to oxidative stress and inflammation. Together, these processes render secondary hemorrhage the most destructive mechanism of secondary injury involving the CNS.

The molecular antecedents of secondary hemorrhage have not been elucidated, although in SCI, a role for nonselective monovalent cation channels has been postulated ${ }^{17}$. Here we identified Trpm4 upregulation and activation as key molecular events responsible for secondary hemorrhage.

\section{RESULTS}

Trpm4 is upregulated after $\mathrm{SCl}$

The rat model of SCI that we studied involved a 'severe' unilateral spinal cord injury at C5 (ref. 17). We chose a hemicord contusion injury because block of contralateral expansion of a unilateral

${ }^{1}$ Department of Neurosurgery, University of Maryland School of Medicine, 22 South Greene Street, Suite S12D, Baltimore, Maryland 21201-1595, USA. ${ }^{2}$ Laboratory of Ion Channel Research, Division of Physiology, Departement Moleculaire Celbiologie, KULeuven, Gasthuisberg, Onderwijs en Navorsing 1, Herestraat 49 bus 802 , 3000 Leuven, Belgium. ${ }^{3}$ Experimentelle Pharmakologie und Toxikologie, Universität des Saarlandes, Kirrberger Strasse, D-66421 Homburg, Germany. ${ }^{4}$ Department of Pathology and ${ }^{5}$ Department of Physiology, University of Maryland School of Medicine, 22 South Greene Street, Suite S12D, Baltimore, Maryland 21201-1595, USA. Correspondence should be addressed to J.M.S. (msimard@smail.umaryland.edu).

Received 14 July 2008; accepted 26 November 2008; published online 25 January 2009; doi:10.1038/nm.1899 
Figure 1 Trpm4 is upregulated in capillaries after $\mathrm{SCl}$. (a) Immunohistochemical localization of Trpm4 in an uninjured control (CTR) and $24 \mathrm{~h}$ after $\mathrm{SCl}$, with montages constructed from multiple individual images, and positive labeling shown in black pseudocolor. Circle marks the impact site; asterisks show sampling area for $\mathbf{b}$ and $\mathbf{c}$. (b) Magnified views of Trpm4 immunolabeled sections taken from uninjured control (CTR) and from the penumbra after SCl. (c) Double immunolabeling of capillaries for Trpm4 (red) and for vonWillebrand factor (green). (d) In situ hybridization for Trpm4 in the penumbra $24 \mathrm{~h}$ after $\mathrm{SCl}$; uninjured control spinal cord tissues (CTR) probed with antisense and post-SCl tissues probed with sense (SE) showed no labeling. (e) RT-PCR of spinal cord tissues $24 \mathrm{~h}$ after SCl from three regions-the impact site (SCI) and rostral $(\mathrm{R})$ and caudal $(\mathrm{C})$ to the impact site - with $\beta$-actin as control; bar graph shows normalized densitometric analysis of RT-PCR data from uninjured spinal cords (CTR) and cords $24 \mathrm{~h}$ after SCl (three rats per group); ${ }^{* *} P<0.01$. Images of immunohistochemistry and in situ hybridization are representative of findings in three rats per group.

injury is easier to detect functionally ${ }^{17}$ than block of rostrocaudal expansion of a midline injury ${ }^{18}$.

Very low levels of Trpm4 expression were found in uninjured controls, but $24 \mathrm{~h}$ after SCI, Trpm 4 was heavily upregulated in tissues surrounding the injury, extending to tissues distant from the actual impact site, including to the contralateral hemicord (Fig. 1a). In the core of the lesion, Trpm 4 upregulation was apparent in all cells, but in penumbral tissues, Trpm 4 upregulation was especially prominent in elongated structures that co-labeled with von Willebrand factor, which suggests that these structures were capillaries (Fig. 1b,c). Study of tissues obtained at earlier times after injury showed no change in Trpm 4 at $1.5 \mathrm{~h}$, but at $3 \mathrm{~h}$ and later, increasingly prominent regions of Trpm4 upregulation were observed near the injury site, with most of the labeling observed in capillaries.

In situ hybridization confirmed that Trpm4 was upregulated after injury, especially in microvessels in the penumbra, with control spinal cord tissues showing no comparable labeling (Fig. 1d). RT-PCR performed on tissues from the injury site and on tissues rostral and caudal to the injury showed that Trpm 4 mRNA doubled within the site of injury (Fig. 1e), with this value markedly underestimating the increase in endothelial cells, which comprise only $0.1 \%$ of CNS volume.

Trpm5 protein and mRNA were essentially absent both before and after SCI.

\section{Trpm4 antisense blocks Trpm4 expression}

We used antisense oligodeoxynucleotide (Trpm4-AS) to assess the role of newly expressed Trpm4 after SCI. We reasoned that an antisense gene suppression strategy would be particularly effective, given that Trpm4 is transcriptionally upregulated after SCI. Sense oligodeoxynucleotide (Trpm4-SE) was used as control. The Trpm4-AS that we used was very effective in reducing Trpm4 mRNA in cultured endothelial cells (Fig. 2a).

We studied cellular localization of fluorescent CY3-conjugated Trpm4-AS (CY3-Trpm4-AS) administered after SCI. After $24 \mathrm{~h}$ of infusion, followed by washout of intravascular contents, CY3-Trpm4AS was abundant in the liver and kidney, as expected ${ }^{19}$, as well as in
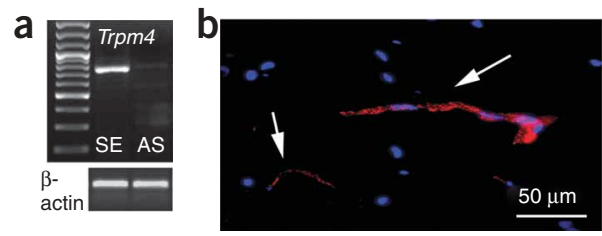

Figure 2 Antisense oligodeoxynucleotide downregulates Trpm4 expression and reduces secondary hemorrhage and capillary fragmentation after SCI. (a) RT-PCR for Trpm4 mRNA in bEnd. 3 cells loaded with Trpm4-SE or Trpm4-AS; $\beta$-actin shown as control; ladder, 100 base pair intervals starting at 200 base pairs. (b) Fluorescence images of the penumbra $24 \mathrm{~h}$ after $\mathrm{SCl}$ in a rat administered CY3-conjugated Trpm4-AS (red) by constant infusion after $\mathrm{SCl}$; rat perfused to remove intravascular contents; nuclei labeled with DAPI (blue); arrows point to capillaries. (c) RT-PCR for Trpm4 mRNA, immunohistochemistry and immunoblots for Trpm4 protein in tissues obtained $24 \mathrm{~h}$ after SCI from rats administered Trpm4-SE or Trpm4-AS; positive control (PC) is from COS-7 cells transfected with hamster Trpm4; $\beta$-actin shown as control; densitometric analysis of immunoblots, normalized for $\beta$-actin, is also shown; ${ }^{* *} P<0.01$. (d) Spinal cord sections and homogenates from untreated control rats (CTR) and rats administered Trpm4-SE, Trpm4-AS or flufenamic acid (FFA); arrows point to petechial hemorrhages distant from the impact sites (circles); also shown is spectrophotometric quantification of extravasated blood at 1,15 and $24 \mathrm{~h}$ after SCI in spinal cord homogenates of untreated controls (CTR, $n=6-12)$, and in rats administered Trpm4-SE $(n=4)$, Trpm4-AS $(n=5)$ or FFA $(n=5)$ after SCI. (e) Sections of penumbra immunolabeled for vimentin showing fragmentation of capillaries in untreated rats (CTR) and rats administered Trpm4-SE versus elongated intact capillaries in rats administered Trpm4-AS or FFA; images representative of findings in three rats per group. 
Figure 3 Cells expressing Trpm4 are highly susceptible to ATP-depletion-induced oncotic cell death. (a) Sodium azide $(1 \mathrm{mM})$ plus 2-deoxyglucose (10 mM) ( $\mathrm{NaAz}+2 \mathrm{DG})$, which produced a rapid drop in cellular ATP, had no effect in cells transfected with EGFPN1 plasmid alone, but caused activation of an inward current that reversed at $\sim 0 \mathrm{mV}$ and was blocked by $\mathrm{N}$-methyl-D-glucamine (NMDG) in COS-7 cells transfected with EGFPN1 + Trpm4 plasmid; the data shown are representative of 11 and 17 cells, with current densities of $-0.91 \pm 0.24$ and $-29.8 \pm 7.8 \mathrm{pA} \mathrm{pF}^{-1}$ (holding potential, $-50 \mathrm{mV}$ ), without and with Trpm4, respectively. (b) Oncotic blebbing, swelling and nuclear labeling with propidium iodide (PI, red) induced by ATP depletion, as above, in COS-7 cells transfected with EGFPN1 + Trpm4 plasmid, but not in cells transfected with EGFPN1 plasmid alone. (c) Quantification of propidium iodide-positive oncotic cell death induced 10 min after ATP depletion in COS-7 cells transfected with EGFPN1 + Trpm4 plasmid or with EGFPN1 plasmid alone; values represent the percentage of the transfected cells (green cytoplasm) with nuclear propidium iodide labeling; experiments were performed in triplicate, with data from $>100$ cells per experiment; ${ }^{* * *} P<0.0001$. the core of the injury, in association with destroyed spinal cord tissue. Uptake of CY3-Trpm4-AS was prominent in capillaries of the penumbra, but almost no CY3-Trpm4-AS appeared to traverse capillaries and label parenchymal cells (Fig. 2b). No fluorescent label was detected in more distant normal capillaries of the spinal cord or brain.

RT-PCR, immunohistochemistry and immunoblots of tissues $24 \mathrm{~h}$ after SCI confirmed that Trpm4-AS was highly effective in reducing Trpm 4 mRNA and protein expression following SCI, and independently validated the antibody we used (Fig. 2c).

\section{Block of Trpm4 reduces secondary hemorrhage}

Spinal cord tissue of untreated control rats or control rats administered Trpm4-SE examined $24 \mathrm{~h}$ after SCI showed prominent bleeding at the surface as well as internally, with internal bleeding consisting of a central region of hemorrhage at the impact site plus numerous petechial hemorrhages in regions remote from the impact site (Fig. 2d). Treatment with Trpm4-AS resulted in a notable reduction in petechial hemorrhages, which was confirmed by examining homogenates of injured spinal cord tissues (Fig. 2d). Quantifying the amount of hemoglobin in spinal cord homogenates reaffirmed that bleeding increased with time after injury, and that Trpm4-AS was highly effective in reducing hemorrhage at $24 \mathrm{~h}$; Trpm4-AS completely eliminated secondary hemorrhage (Fig. 2d). We also tested the effect of flufenamic acid, an open-channel blocker of nonselective cation channels including Trpm4 (ref. 20). As with Trpm4-AS, flufenamic acid was highly effective in reducing hemorrhage (Fig. 2d), which suggests that newly upregulated $\operatorname{Trpm} 4$ was acting as a functional membrane channel.

We studied the structural integrity of capillaries in spinal cord sections from rats administered Trpm4-SE or Trpm4-AS. In untreated control rats and rats administered Trpm4-SE, broken fragments of capillaries were prominent in penumbral tissues adjacent to the site of injury, which is consistent with catastrophic failure of capillary integrity, and which accounts for high levels of extravasated blood (Fig. 2e). By contrast, in rats treated with Trpm4-AS or flufenamic acid, intact elongated capillaries predominated in penumbral tissues, thus accounting for the significant $(P<0.01)$ reduction in extravasated blood (Fig. 2e).

\section{Trpm4 expression predisposes to cell death}

Opening of Trpm4 channels is known to result in cell-protective depolarization $^{21}$. However, the capillary fragmentation observed in association with Trpm 4 expression suggested that Trpm 4 might be injurious under certain conditions. We hypothesized that sustained opening of Trpm4 channels, as would arise with the severe ATP depletion associated with SCI (refs. 22-24), could lead not only to depolarization but also to continuous influx of $\mathrm{Na}^{+}$, which, if unchecked, could induce oncotic swelling and oncotic death of endothelial cells, resulting in capillary fragmentation.

We tested this hypothesis in COS-7 cells heterologously expressing Trpm4, with expression of functional channels being verified electrophysiologically. In control cells, ATP depletion had no effect on membrane currents, but in cells expressing Trpm4, ATP depletion resulted in activation of a sustained inward cationic current that reversed near $0 \mathrm{mV}$, and that was blocked by $N$-methyl-D-glucamine, which indicates that the channels were Trpm4 (Fig. 3a).

In COS-7 cells expressing Trpm4, but not in controls, ATP depletion caused marked cell blebbing, oncotic swelling and membrane leakage, resulting in nuclear labeling by propidium iodide, which is consistent with oncotic cell death (Fig. 3b). In control cells, ATP depletion was well tolerated, with only $7 \%$ of cells exhibiting propidium iodidepositive cell death. By contrast, $50 \%$ or more of cells expressing Trpm 4 died within 10 min of ATP depletion (Fig. 3c). These findings indicate that Trpm4 expression renders cells highly susceptible to ATPdepletion-induced oncotic cell death. Moreover, these data suggest that the fragmentation of capillaries that express $\operatorname{Trpm} 4$, as observed in vivo after SCI (see Figs. 1b,c and 2e), was due to oncotic death of endothelial cells associated with opening of Trpm4 channels.

\section{Block of Trpm4 improves outcome after SCI}

We further evaluated the role of Trpm4 in SCI by studying neurobehavioral function and lesion volume in rats treated with intravenous Trpm4-AS for only $24 \mathrm{~h}$, beginning shortly after injury.

Rats were evaluated serially over the course of one week. We quantified vertical exploration, a complex exercise that requires balance, truncal stability, bilateral hindlimb dexterity and strength, and at least unilateral forelimb dexterity and strength, which in combination are excellent markers of cervical spinal cord function ${ }^{17}$. We also evaluated performance in two other standard tests, beam walking and inclined plane, the latter requiring more and more dexterous function of the limbs and paws as the angle of the plane is increased ${ }^{25}$. Performance on all three functional tests was consistently better with Trpm4-AS. By day 7, Trpm4-AS-treated rats exhibited near-normal performance, which was never achieved by control 
a

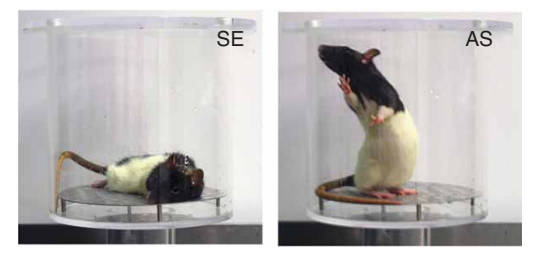

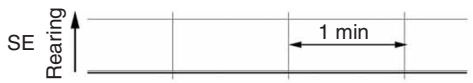

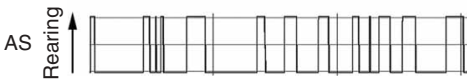

b
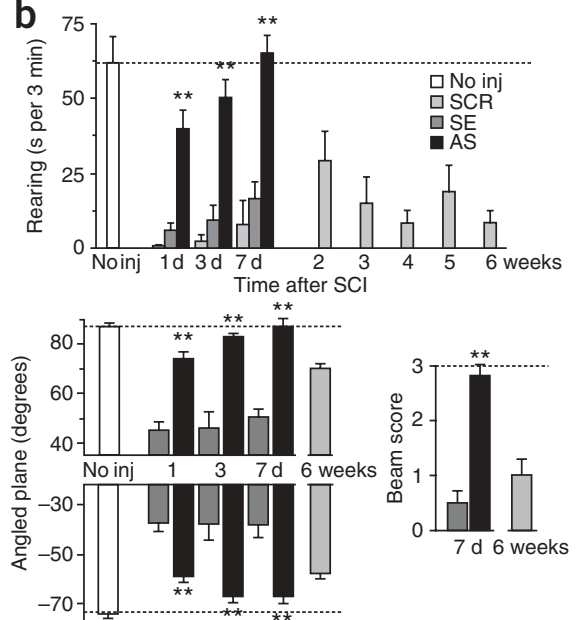

C
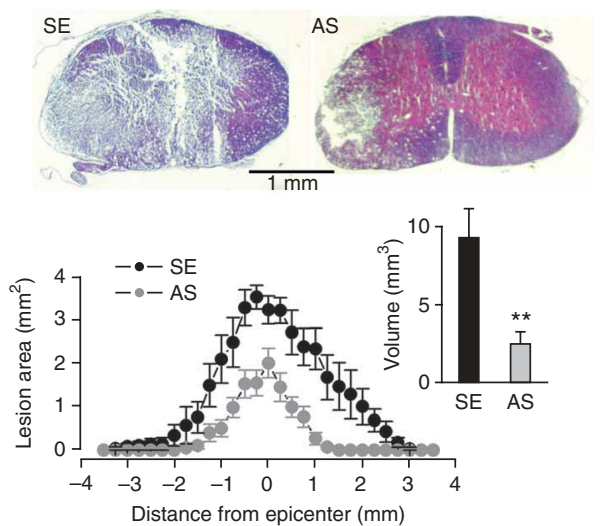

Figure 4 Trpm4-AS improves neurobehavioral performance and reduces lesion volume in rats after SCl. (a) Rearing $24 \mathrm{~h}$ after $\mathrm{SCl}$ in rats administered either Trpm4-AS or Trpm4-SE for $24 \mathrm{~h}$ after SCI. (b) Quantified rearing, performance on up-angled and down-angled planes, and performance on beam walking tests at various times after SCl in rats administered Trpm4-AS, Trpm4-SE or scrambled (SCR) oligodeoxynucleotide for $24 \mathrm{~h}$ after SCl; 5-6 rats per group; values for uninjured rats (No inj) or perfect scores are shown as dotted lines; ${ }^{*} P<0.01$. (c) Hematoxylin and eosin-stained sections from representative rats $7 \mathrm{~d}$ after SCl that were administered Trpm4-AS or Trpm4-SE for $24 \mathrm{~h}$, along with average lesion areas and lesion volumes; data are from the same rats as in $\mathbf{b}$.

rats treated with scrambled oligodeoxynucleotide, even after 6 weeks of recovery (Fig. 4a,b). In the same animals, treatment with Trpm4-AS for only $24 \mathrm{~h}$ resulted in a threefold reduction in lesion volume when measured $7 \mathrm{~d}$ after injury (Fig. 4c).

\section{Trpm4 knockout improves outcome after SCI}

To confirm our findings from the experiments with transient gene suppression, we also studied SCI in Trpm4 knockout $\left(\operatorname{Trpm} 4^{-1-}\right)$ mice. For these experiments, we used a unilateral spinal cord injury at T9.

As in rats, SCI in wild-type (WT) mice was associated with marked upregulation of Trpm 4 in the vicinity of the injury (Fig. 5a). Spinal cords of WT mice examined $24 \mathrm{~h}$ after injury invariably showed more hemorrhage than those harvested 30 -min after injury, which is consistent with progressive hemorrhage (Fig. 5b). By contrast, spinal cords of Trpm $4^{-1-}$ mice showed no more blood at $24 \mathrm{~h}$ than those of WT mice at 30 min after injury (Fig. 5b). At $24 \mathrm{~h}$ after SCI, Trpm $4^{-1-}$ mice showed less than half the amount of extravasated blood observed in WT mice (Fig. 5c), which is in agreement with our data on parenchymal hemorrhage in rats treated with Trpm4-AS (see Fig. 2).

We evaluated functional performance using a standardized, reliable instrument commonly used in SCI research on mice, the BMS scale ${ }^{26}$, modified to assess individual hindlimb function separately. Trpm $4^{-1-}$
Figure 5 Trpm4 ${ }^{-/-}$reduces secondary hemorrhage and improves neurobehavioral performance in mice after SCl. (a) Immunohistochemical localization of Trpm4 $24 \mathrm{~h}$ after $\mathrm{SCl}$ in a WT mouse, with montage constructed from multiple individual images, and positive labeling shown in black pseudocolor; circle denotes impact site. (b) Spinal cords from WT mice harvested $30 \mathrm{~min}$ and $24 \mathrm{~h}$ after $\mathrm{SCl}$, as indicated, showing progressive hemorrhage, and spinal cords from Trpm4 $4^{-/-}$mice harvested $24 \mathrm{~h}$ after $\mathrm{SCl}$, as indicated, showing reduced hemorrhage compared to WT mice; intravascular blood removed by saline perfusion. (c) Spinal cord homogenates from WT mice and Trpm4 $4^{-/}$ mice and quantitative analysis for hemoglobin $24 \mathrm{~h}$ after $\mathrm{SCl}$; five mice per group; ${ }^{* *} P<0.01$. (d) Photographs of WT (red mark on tail) and Trpm4 ${ }^{-l-}$ (blue mark on tail) mice showing truncal posture, ipsilateral (black arrow) and contralateral (white arrow) hindlimb position, and muscle tone in tail following left-sided hemicord contusion at T9. Ipsilateral and contralateral functional performances quantified using unilateral BMS scores are also shown (score in uninjured rat, 9); Fisher's exact test; ${ }^{*} P<0.05 ;{ }^{*} P<0.01$. (e) Low-power and high-power views of sections stained with hematoxylin and eosin from uninjured control (CTR) and $7 \mathrm{~d}$ after $\mathrm{SCl}$ in WT and Trpm4 $4^{-1-}$ mice; lesion areas and lesion volumes are also shown. ${ }^{* *} P<0.001$.
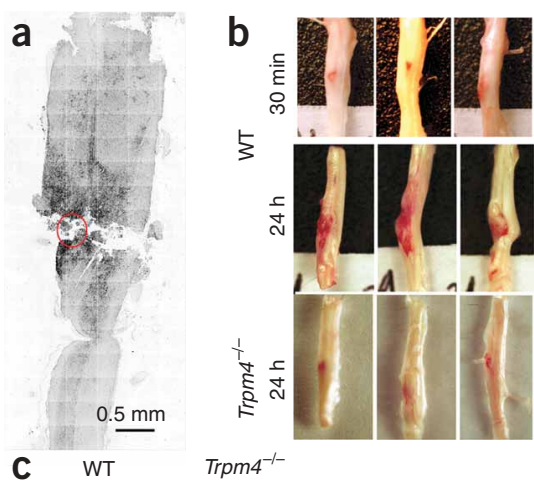

\section{e}
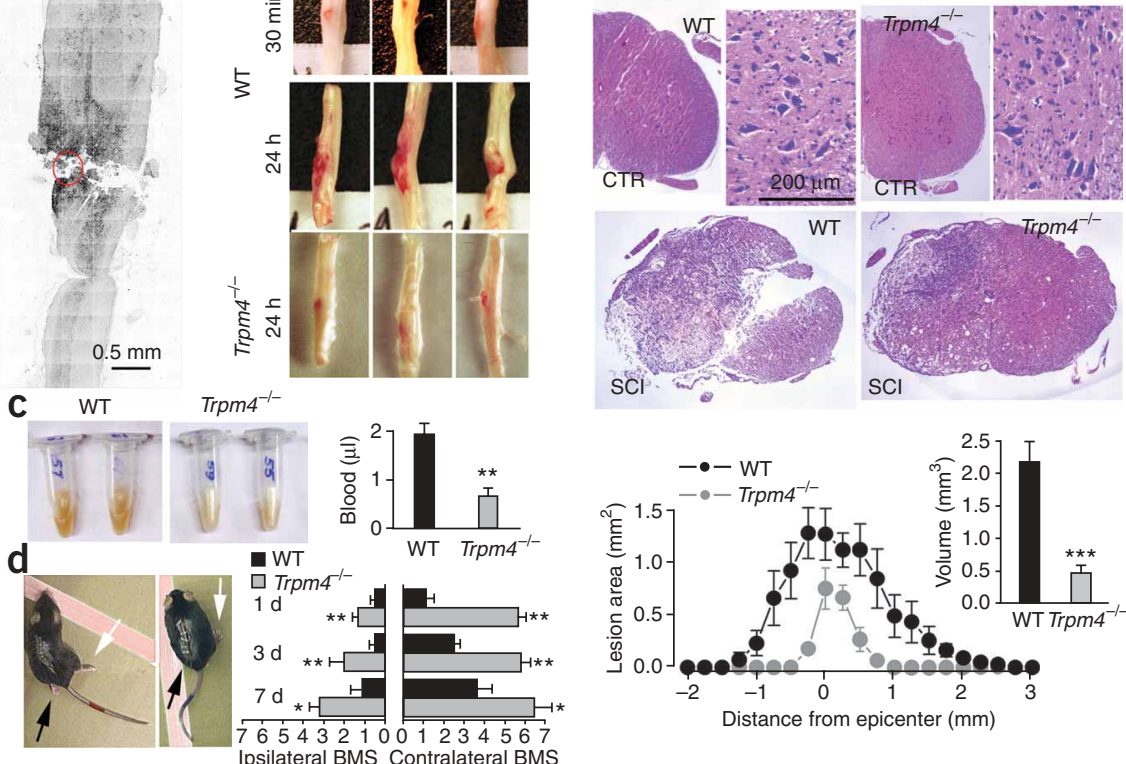
mice exhibited significantly $(P<0.05)$ better performance than WT mice (Fig. 5d). In WT mice $24 \mathrm{~h}$ after injury, the hindlimb ipsilateral to the injury typically exhibited flaccid paralysis (no ankle movement), whereas in Trpm $4^{-1-}$ mice, the ipsilateral hindlimb exhibited ankle movement without plantar placement. More notably, in WT mice $24 \mathrm{~h}$ after injury, the contralateral hindlimb typically exhibited only minor ankle movement without plantar placement, whereas in Trpm $4^{-1-}$ mice, the contralateral hindlimb exhibited consistent plantar stepping with at least some coordination. Quantitative evaluation of BMS scores over the course of one week after injury confirmed the marked protective effect of Trpm $4^{-1-}$ and demonstrated the durability of this effect (Fig. 5d). Near-total recovery of function on the contralateral side by day 7 attested to minimal spread of progressive hemorrhage in Trpm $4^{-1-}$ mice with unilateral injury. The excellent neurological outcome in the same Trpm $4^{-/}$mice was attributable to a significant $(P<0.001)$ reduction in lesion size (Fig. 5e), which exceeded that observed with Trpm4-AS in rats.

\section{DISCUSSION}

Trpm4 is one of only two molecularly identified nonselective cation channels that conducts monovalent but not divalent cations ${ }^{3-5}$. Although Trpm4 is constitutively expressed at high levels in some native tissues, normally the CNS shows only low levels of Trpm4 expression $^{27}$. However, Trpm4 is upregulated under certain pathological conditions: (i) Trpm4 is expressed in greater abundance in cardiac myocytes from hypertensive rats compared with normotensive controls, where a role in delayed after-depolarization has been postulated $^{28}$; (ii) as we show here, Trpm4 is greatly upregulated in capillary endothelial cells of the spinal cord following SCI, where we demonstrated a critical role in capillary fragmentation, formation of petechial hemorrhages and secondary hemorrhage.

In electrically nonexcitable cells such as $\mathrm{T}$ cells $\mathrm{s}^{4,29}$, mast cells $\mathrm{s}^{5}$ and endothelial cells ${ }^{30}$ that do not express voltage-dependent $\mathrm{Ca}^{2+}$ channels, and where $\mathrm{Ca}^{2+}$ entry occurs via store- or receptor-operated channels, depolarization of the cell membrane decreases the rate of $\mathrm{Ca}^{2+}$ influx ${ }^{3}$. The probability of opening Trpm4 increases with high $\mathrm{Ca}^{2+}$ and low ATP in cytoplasm ${ }^{21}$. Notably, both of the pathological conditions in which Trpm 4 is upregulated, myocyte hypertrophy ${ }^{31}$ and endothelial cell activation ${ }^{32,33}$, are associated with elevated levels of cytosolic $\mathrm{Ca}^{2+}$. These cells appear to be upregulating a $\mathrm{Ca}^{2+}$ activated mechanism that can act as negative feedback on $\mathrm{Ca}^{2+}$ influx. It is thus tempting to consider that upregulation of $\operatorname{Trpm} 4$ may be evolutionarily favored in metabolically injured cells because it can serve the important protective role of promoting depolarization and thereby defending against $\mathrm{Ca}^{2+}$ overload $^{34}$.

Normally, cytoplasmic concentrations of ATP are such that Trpm4 channel activity can be modulated by physiological changes in $\mathrm{Ca}^{2+}$ (ref. 21). However, in the context of severe ATP depletion, Trpm 4 channel opening may persist indefinitely ${ }^{4,5}$, with no "run-down" and no mechanism for inactivating or deactivating the channel except restoration of ATP or depletion of phosphatidylinositol-4,5bisphosphate ${ }^{29,35}$. Thus, under pathological conditions such as in SCI, when ATP depletion may be severe ${ }^{22-24}$, the normal physiological modulation of Trpm4 channel activity may be replaced by nearmaximal activation. Unchecked activation of Trpm 4 may lead not only to complete cell depolarization, but also to unrestricted influx of sodium, resulting eventually in oncotic cell swelling and oncotic cell death. Trpm 4 expression per se is not deleterious, as long as ATP levels are adequate to limit channel opening. However, as we show here, cells expressing Trpm 4 are highly susceptible to oncotic cell death following severe ATP depletion. Severe ATP depletion apparently converts what may be an adaptive mechanism of Trpm4 upregulation that defends against $\mathrm{Ca}^{2+}$ overload into a maladaptive mechanism of oncotic cell death when ATP is depleted.

The histopathological sequelae of crush and contusion injury to the spinal cord have been reviewed ${ }^{10,36}$. Within minutes to hours after injury, individual petechial hemorrhages form around the site of injury as well as in more distant areas ${ }^{37,38}$. Petechial hemorrhages continue to form, and the lesion gradually enlarges, with a characteristic region of hemorrhage "capping" the advancing front of the lesion ${ }^{10}$. A small hemorrhagic lesion involving primarily the capillaryrich central gray matter observed 15 min after injury typically enlarges progressively over 3-24 $\mathrm{h}^{38-40}$. Overall, the pattern and extent of secondary hemorrhage would not be predicted based simply on the volume of tissue involved in the primary injury or on the physical proximity to the injury site.

We hypothesize that an advancing front of Trpm 4 upregulation in capillary endothelium has a leading role in lesion expansion, and that the autodestruction of activated capillaries is due to molecular events within endothelial cells. Support for these hypotheses is provided by our findings that: (i) Trpm4 is abundantly upregulated in capillaries, initially immediately adjacent to the primary injury and later in more distant penumbra; (ii) Trpm4 expression greatly sensitizes cells to ATP-depletion-induced oncotic death; (iii) Trpm4 upregulation in capillaries is associated with fragmentation of capillaries and results in formation of petechial hemorrhages and (iv) block of Trpm4 eliminates fragmentation of capillaries and formation of hemorrhages.

The findings reported here with Trpm4 parallel recent observations on sulfonylurea receptor 1 (Sur1) after SCI ${ }^{17}$. As with Trpm4, Sur1 is upregulated, especially in penumbral capillaries, and block of Sur1 reduces secondary hemorrhage, reduces lesion size and greatly improves functional outcome. It has been conjectured that Trpm4 may comprise the pore-forming subunit of the Surl-regulated $\mathrm{NC}_{\mathrm{Ca}-\mathrm{ATP}}$ channel $^{41}$. The data presented here support this conjecture, although additional molecular evidence will be required to advance this hypothesis.

SCI continues to devastate the lives of millions of people worldwide. Short of total prevention, the best hope for improving outcome from SCI is to minimize the secondary injury that occurs within the first few hours of trauma. So far, the best attempts have yielded modest improvements ${ }^{42}$. The data presented here on block of $\operatorname{Trpm} 4$, as well as previous data on block of Surl (ref. 17), indicate that in preventing secondary hemorrhage, significant improvements in functional outcome may be expected.

\section{METHODS}

Rodent models of SCI. This study was approved by the Institutional Animal Care and Use Committee of the University of Maryland. Adult female LongEvans rats (275-350 g) were anesthetized (ketamine, $60 \mathrm{mg} \mathrm{kg}^{-1}$, plus xylazine, $7.5 \mathrm{mg} \mathrm{kg}^{-1}$, intraperitoneally) and underwent a hemi-cervical cord contusion as described ${ }^{17}$. We exposed the dura at $\mathrm{C} 4-\mathrm{C} 5$ via a left hemilaminectomy and created a hemicervical cord contusion using a blunt force impactor (modified NYU device; $1.3-\mathrm{mm}$ impactor head; $10 \mathrm{~g}$ weight dropped $25 \mathrm{~mm}$ ). After SCI, we gave animals $10 \mathrm{ml}$ of glucose-free normal saline subcutaneously. We maintained rectal temperature at $\sim 37^{\circ} \mathrm{C}$. Typical blood gases (i-STAT, Heska Corp), sampled before injury, were $\mathrm{pO}_{2}>90 \mathrm{~mm} \mathrm{Hg}$ and $\mathrm{pCO}_{2}<47 \mathrm{~mm} \mathrm{Hg}$, and glucose levels were $150-200 \mathrm{mg} \mathrm{dl}^{-1}$.

Trpm $4^{-1-}$ mice, obtained as previously described ${ }^{5}$, showed neurological function, gait and spinal cord histology that were indistinguishable from that of WT (see Fig. 5e), and maximum BMS scores of 9. For SCI experiments, female WT (background, C57BL/6) and Trpm $4^{-1-}$ mice (backcrossed for 6 generations on the C57BL/6 background), 24-28 g, were anesthetized (ketamine, $60 \mathrm{mg} \mathrm{kg}^{-1}$, plus xylazine, $7.5 \mathrm{mg} \mathrm{kg}^{-1}$, intraperitoneally), the dura at T9 was 
exposed via a left hemilaminectomy and a hemithoracic spinal cord contusion was created (modified NYU device; 0.6-mm impactor head; $10 \mathrm{~g}$ weight dropped $5 \mathrm{~mm}$ ).

For gene suppression of Trpm4, we used antisense oligodeoxynucleotide (5'-TTGTGGTAACACTCTCCAAA-3') phosphorothioated at four distal bonds. We used sense as control. We verified the functionality of Trpm4-AS by measuring Trpm 4 mRNA by RT-PCR in bEnd. 3 cells loaded with Trpm4-AS or with Trpm4-SE (using LipofectAMINE, Invitrogen) and exposed to tumor necrosis factor- $\alpha\left(20 \mathrm{ng} \mathrm{ml}^{-1}\right)$. For SCI rats, a few minutes after injury, we gave a loading dose of $300 \mu \mathrm{g}$ of oligodeoxynucleotide in $300 \mu \mathrm{l}$ intravenously and implanted mini-osmotic pumps (Alzet; Durect Corporation) with jugular vein catheters (infusion: $\left.40 \mu \mathrm{g} \mathrm{hr}^{-1} \times 24 \mathrm{~h}\right)^{17}$.

For block of Trpm4, we used flufenamic acid, $10 \mathrm{mg} \mathrm{kg}^{-1}$ intraperitoneally, given at $0.1,6$ and $16 \mathrm{~h}$ after SCI.

Immunohistochemistry. We immunolabled cryosections prepared from perfusion-fixed spinal cords ${ }^{17,43}$ with primary antibodies directed against Trpm4 (1:100; overnight at $4{ }^{\circ} \mathrm{C}$; SC-27540; Santa Cruz Biotechnology), vWf (1:200; F3520, Sigma) and vimentin (1:100; overnight at $4{ }^{\circ} \mathrm{C}$; Sigma).

Immunoblots. $80 \mu \mathrm{g}$ of protein from cord lysates were separated on a $3-8 \%$ Tris-acetate gel and blotted onto a nitrocellulose membrane blocked with 7\% nonfat milk. We visualized Trpm4 using the same antibody.

RT-PCR. We used forward and reverse primers, designed from different exons, as follows: forward ( $5^{\prime}$-GTCATCGTGAGCAAGATGATGAA-3') and reverse (5'-GTCCACCTTCTGGGACGTGC-3').

In situ hybridization for Trpm4 (XM_574447). We processed cryosections with digoxigenin-labeled probes (antisense: 5 '-CCAGGGCAGGCCGCGAATG GAATTCCCGGATGAGGCTGTAGCGCTGCG-3'; GeneDetect).

Spinal cord tissue blood. We determined the amount of blood in spinal cord tissue as described ${ }^{17}$.

Trpm4 expression. We recloned the $m$ Trpm 4 insert from $m$ Trpm4-GFP plasmid $^{29}$ into a plasmid containing enhanced green fluorescence protein (EGFPN1; Clontech). We used EGFPN1 alone as control. We transiently transfected COS7 cells with plasmid DNA using FuGENE (Roche) per the manufacturer's instructions. We studied cells $48 \mathrm{~h}$ after transfection. We assessed ATP depletion following exposure to $\mathrm{Na}$ azide and 2-deoxyglucose using an ATP bioluminescent assay kit (Sigma-Aldrich).

Patch clamp electrophysiology. We performed patch clamp electrophysiology as described ${ }^{17,43}$.

Oncotic cell death. ATP was depleted using $\mathrm{Na}$ azide $(1 \mathrm{mM})$ plus 2-deoxyglucose $(10 \mathrm{mM})$. We collected cells and resuspended them in labeling reagent containing propidium iodide for $10 \mathrm{~min}$ and then counted. We divided the number of cells exhibiting a green fluorescent signal (EGFPN) plus red nuclear staining (propidium iodide) by the total number of cells exhibiting a green fluorescent signal.

Neurobehavioral assessment. Blinded evaluators performed all measurements. For vertical exploration (rearing) ${ }^{44}$, we videotaped animals while in a translucent cylinder $(20 \times 20 \mathrm{~cm})$, with rearing quantified as the number of seconds spent with both front paws elevated above shoulder height during the first 3 -min period of observation. Beam walking, inclined plane ${ }^{25}$ and BMS scoring were determined as described ${ }^{26}$.

Lesion volumes. We calculated spinal cord lesion volumes $7 \mathrm{~d}$ after SCI as described ${ }^{17}$.

Statistical analyses. Statistical significance was evaluated using Student's $t$-test or ANOVA with Bonferroni comparisons, as appropriate, except for BMS scores, which were evaluated using Fisher's exact test. Data are presented as mean \pm s.e.m.

\section{ACKNOWLEDGMENTS}

This work was supported by grants to J.M.S. from the US National Heart, Lung, and Blood Institute (HL082517), the US National Institute of Neurological Disorders and Stroke (NS048260), the US Department of Veterans Affairs and the Christopher and Dana Reeve Foundation; to V.G. from the US National Institute of Neurological Disorders and Stroke (NS061934); and to M.F. and V.F. from the Deutsche Forschungsgemeinschaft. R.V. is supported by the FWO Vlaanderen. The $m$ Trpm4-GFP plasmid was kindly provided by E.R. Liman (University of Southern California).

\section{AUTHOR CONTRIBUTIONS}

V.G. and J.M.S. conceived of and directed the study, participated in neurobehavioral assessments, analyzed the data and wrote the manuscript; S.K.W., Z.G. and Z.C. performed molecular and cell death experiments; O.T. performed rodent surgeries; S.I. performed immunolabeling and in situ hybridization; A.I. performed patch clamp experiments; R.V., M.F., V.F. and B.N. developed the $\operatorname{Trpm} 4^{-1-}$ mice and contributed to early drafts of the manuscript.

\section{COMPETING INTERESTS STATEMENT}

The authors declare competing financial interests: details accompany the full-text HTML version of the paper at http://www.nature.com/naturemedicine/.

Published online at http://www.nature.com/naturemedicine/

Reprints and permissions information is available online at http://npg.nature.com/ reprintsandpermissions/

1. Nilius, B., Owsianik, G., Voets, T. \& Peters, J.A. Transient receptor potential cation channels in disease. Physiol. Rev. 87, 165-217 (2007).

2. Venkatachalam, K. \& Montell, C. TRP channels. Annu. Rev. Biochem. 76, 387-417 (2007).

3. Launay, P. et al. TRPM4 is a $\mathrm{Ca}^{2+}$-activated nonselective cation channel mediating cell membrane depolarization. Cell 109, 397-407 (2002)

4. Launay, P. et al. TRPM4 regulates calcium oscillations after T cell activation. Science 306, 1374-1377 (2004).

5. Vennekens, R. et al. Increased IgE-dependent mast cell activation and anaphylactic responses in mice lacking the calcium-activated nonselective cation channel TRPM4. Nat. Immunol. 8, 312-320 (2007).

6. Nilius, B. TRP channels in disease. Biochim. Biophys. Acta 1772, 805-812 (2007).

7. Nicotera, P. \& Bano, D. The enemy at the gates. $\mathrm{Ca}^{2+}$ entry through TRPM7 channels and anoxic neuronal death. Cell 115, 768-770 (2003).

8. Aarts, M. et al. A key role for TRPM7 channels in anoxic neuronal death. Cell 115 863-877 (2003).

9. Oertel, M. et al. Progressive hemorrhage after head trauma: predictors and consequences of the evolving injury. J. Neurosurg. 96, 109-116 (2002).

10. Guth, L., Zhang, Z. \& Steward, O. The unique histopathological responses of the injured spinal cord. Implications for neuroprotective therapy. Ann. NY Acad. Sci. 890, 366-384 (1999).

11. Griffiths, I.R., Burns, N. \& Crawford, A.R. Early vascular changes in the spinal grey matter following impact injury. Acta Neuropathol. 41, 33-39 (1978).

12. Hayes, K.C. \& Kakulas, B.A. Neuropathology of human spinal cord injury sustained in sports-related activities. J. Neurotrauma 14, 235-248 (1997).

13. Tator, C.H. \& Koyanagi, I. Vascular mechanisms in the pathophysiology of human spinal cord injury. J. Neurosurg. 86, 483-492 (1997).

14. Tator, C.H. \& Fehlings, M.G. Review of the secondary injury theory of acute spinal cord trauma with emphasis on vascular mechanisms. J. Neurosurg. 75, 15-26 (1991).

15. Regan, R.F. \& Guo, Y. Toxic effect of hemoglobin on spinal cord neurons in culture J. Neurotrauma 15, 645-653 (1998).

16. Wang, X., Mori, T., Sumii, T. \& Lo, E.H. Hemoglobin-induced cytotoxicity in rat cerebral cortical neurons: caspase activation and oxidative stress. Stroke 33, 1882-1888 (2002).

17. Simard, J.M. et al. Endothelial sulfonylurea receptor 1-regulated NC Ca-ATP channels mediate progressive hemorrhagic necrosis following spinal cord injury. J. Clin. Invest 117, 2105-2113 (2007)

18. Swartz, K.R. et al. Gender differences in spinal cord injury are not estrogen-dependent. J. Neurotrauma 24, 473-480 (2007).

19. Zhao, Q. et al. Cellular distribution of phosphorothioate oligonucleotide following intravenous administration in mice. Antisense Nucleic Acid Drug Dev. 8, 451-458 (1998).

20. Pena, F. \& Ordaz, B. Nonselective cation channel blockers: potential use in nervous system basic research and therapeutics. Mini Rev. Med. Chem. 8, 812-819 (2008).

21. Vennekens, R. \& Nilius, B. Insights into TRPM4 function, regulation and physiological role. Handb. Exp. Pharmacol. 179, 269-285 (2007).

22. Colak, A. et al. Neuroprotective effects of GYKI 52466 on experimental spinal cord injury in rats. J. Neurosurg. 98, 275-281 (2003).

23. Osterholm, J.L., Alderman, J.B., Triolo, A.J., D'Amore, B.R. \& Williams, H.D. Oxyge nated fluorocarbon nutrient solution in the treatment of experimental spinal cord injury. Neurosurgery 15, 373-380 (1984). 
24. Anderson, D.K., Means, E.D., Waters, T.R. \& Spears, C.J. Spinal cord energy metabolism following compression trauma to the feline spinal cord. J. Neurosurg. 53, 375-380 (1980).

25. Rivlin, A.S. \& Tator, C.H. Objective clinical assessment of motor function after experimental spinal cord injury in the rat. J. Neurosurg. 47, 577-581 (1977).

26. Basso, D.M. et al. Basso Mouse Scale for locomotion detects differences in recovery after spinal cord injury in five common mouse strains. J. Neurotrauma 23, 635-659 (2006).

27. Kunert-Keil, C., Bisping, F., Kruger, J. \& Brinkmeier, H. Tissue-specific expression of TRP channel genes in the mouse and its variation in three different mouse strains. BMC Genomics 7, 159 (2006).

28. Guinamard, R., Demion, M., Magaud, C., Potreau, D. \& Bois, P. Functional expression of the TRPM4 cationic current in ventricular cardiomyocytes from spontaneously hypertensive rats. Hypertension 48, 587-594 (2006).

29. Zhang, Z., Okawa, H., Wang, Y. \& Liman, E.R. Phosphatidylinositol 4,5-bisphosphate rescues TRPM4 channels from desensitization. J. Biol. Chem. 280, 39185-39192 (2005).

30. Nilius, B. \& Droogmans, G. Ion channels and their functional role in vascular endothelium. Physiol. Rev. 81, 1415-1459 (2001).

31. Guinamard, R. \& Bois, P. Involvement of transient receptor potential proteins in cardiac hypertrophy. Biochim. Biophys. Acta 1772, 885-894 (2007).

32. Tiruppathi, C., Minshall, R.D., Paria, B.C., Vogel, S.M. \& Malik, A.B. Role of $\mathrm{Ca} 2+$ signaling in the regulation of endothelial permeability. Vascul. Pharmacol. 39, 173-185 (2002).

33. Tiruppathi, C., Ahmmed, G.U., Vogel, S.M. \& Malik, A.B. $\mathrm{Ca}^{2+}$ signaling, TRP channels, and endothelial permeability. Microcirculation 13, 693-708 (2006).
34. Nilius, B., Prenen, J., Voets, T. \& Droogmans, G. Intracellular nucleotides and polyamines inhibit the Ca2+-activated cation channel TRPM4b. Pflugers Arch. 448, 70-75 (2004).

35. Nilius, B. et al. The Ca2+-activated cation channel TRPM4 is regulated by phosphatidylinositol 4,5-biphosphate. EMBO J. 25, 467-478 (2006).

36. Steward, O. et al. Genetic approaches to neurotrauma research: opportunities and potential pitfalls of murine models. Exp. Neurol. 157, 19-42 (1999).

37. Khan, M., Griebel, R., Rozdilsky, B. \& Politis, M. Hemorrhagic changes in experimental spinal cord injury models. Can. J. Neurol. Sci. 12, 259-262 (1985).

38. Kawata, K. et al. Experimental study of acute spinal cord injury: a histopathological study. No Shinkei Geka 21, 45-51 (1993).

39. Balentine, J.D. Pathology of experimental spinal cord trauma. I. The necrotic lesion as a function of vascular injury. Lab. Invest. 39, 236-253 (1978).

40. lizuka, H., Yamamoto, H., Iwasaki, Y., Yamamoto, T. \& Konno, H. Evolution of tissue damage in compressive spinal cord injury in rats. J. Neurosurg. 66, 595-603 (1987).

41. Simard, J.M., Tarasov, K.V. \& Gerzanich, V. Non-selective cation channels, transient receptor potential channels and ischemic stroke. Biochim. Biophys. Acta 1772 947-957 (2007).

42. Hall, E.D. \& Springer, J.E. Neuroprotection and acute spinal cord injury: a reappraisal. NeuroRx 1, 80-100 (2004).

43. Simard, J.M. et al. Newly expressed SUR1-regulated NC(Ca-ATP) channel mediates cerebral edema after ischemic stroke. Nat. Med. 12, 433-440 (2006).

44. Nikulina, E., Tidwell, J.L., Dai, H.N., Bregman, B.S. \& Filbin, M.T. The phosphodiesterase inhibitor rolipram delivered after a spinal cord lesion promotes axonal regeneration and functional recovery. Proc. Natl. Acad. Sci. USA 101, 8786-8790 (2004). 